\title{
On the Reform of College Basketball Teaching from the Perspective of Leisure Sports
}

\author{
Liang Wei ${ }^{1}$ \\ ${ }^{1}$ Chengdu Medical College, Chengdu, Sichuan Province, China
}

Keywords: Leisure Sports Perspective; Colleges And Universities; Basketball Teaching.

\begin{abstract}
Basketball is one of the most popular sports for college students in China; basketball lessons are also sought after among physical education courses. However, under the traditional teaching concept, basketball teaching focuses on the improvement of students' basketball skills, and fails to integrate leisure and entertainment elements. Thus, the teaching effect is not favorable. This paper first describes the foundation of combining leisure sports with basketball teaching, and then discusses the objectives, contents and methods of college basketball teaching reform from the perspective of leisure sports.
\end{abstract}

\section{Introduction}

The combination of leisure sports and basketball teaching is an important method of college physical education reform. Basketball lessons should be designed according to students' actual needs, conform to the development direction of leisure sports and sports entertainment, and delete teaching contents which are not suitable for students. Only in this way, can we arouse students' learning interests, and help them to enjoy the fun of learning in basketball classes.

\section{The Foundation of Combining Leisure Sports with Basketball Teaching}

Our country has a long history of examination oriented education. But now, talents cultivated under the exam oriented education are no longer in line with the needs of our country's social development. Education reform is the only way to promote the development of education. Therefore, quality education has become the focus of education reform, while the reform on physical education has been highly valued by colleges and universities. Basketball teaching occupies a large proportion in physical education curriculum. But under the influence of traditional teaching concept, teachers pay too much attention to students' learning of standard movements and the improvement of their basketball skills. Students are required to repeat settled actions again and again. The boring training deprives the original meaning of basketball training: help students relax and improve their physical qualities. In this traditional way, students are easily to get bored, and it is difficult to achieve the teaching effect of quality education. [1] Therefore, it is very necessary to combine leisure sports with basketball teaching, in order to realize the real purpose of basketball teaching, meet students' needs on physical education, stimulate their interests in basketball learning, and improve their physical and psychological qualities.

\section{Reform of College Basketball Teaching Objectives from the Perspective of Leisure Sports}

In order to combine leisure sports with college basketball teaching, it is necessary to reform basketball lessons to further improve and reform teaching objectives.

Knowledge, understanding and awareness. First of all, it is necessary to understand the importance of leisure sport and its impacts on the reform of basketball teaching, so that we can find the right direction of reform. Leisure sports are very important in our modern society, since they conform to the development trend of society, meet the needs of personnel training in China, and can make positive contribution to the development of our society. [2] Before introducing leisure sports into universities and colleges, we should have a full understanding of leisure sport, get to know its values in social development, and its significance in college physical education. Universities and 
colleges should learn the advantages and disadvantages of leisure sports at the same time. Leisure sport is a new concept in universities, and it has many deficiencies need to be improved. Colleges and universities should try to avoid the negative impacts of these deficiencies on students.

Behaviors, habits and skills. The basic purpose of basketball teaching is to relax students, improve their physical qualities, and help them to master basketball skills in practice. Teachers should make plans of leisure sports, which can help students to steel themselves in basketball, so as to improve their physical qualities. Interests can help students to overcome many difficulties, so it is very important for students to cultivate their interests in basketball. Colleges and universities should encourage students to participate in the process of basketball teaching, in order to cultivate their interests in basketball learning. If students have the desire to learn, the teacher can teach better. Students' interests in basketball can not only improve the efficiency of basketball teaching in class, but also enable students to participate in basketball activities in their spare time, which can better improve their physical qualities.

Emotions and values. Basketball is a healthy exercise. It can not only improve the physical qualities of students, but also improve the levels of their mental health. In basketball game, student can experience positive feelings like happy, freedom, success, satisfaction and excitement. Basketball is a collective activity. It helps students to form good qualities like cooperation and team spirit. These qualities have positive impacts on their personal development. Through basketball matches, students can learn the right attitudes towards competition and cooperation, success and failure. At the same time, basketball can help students to develop positive and optimistic attitudes towards life, which will bring great benefits to their future work and life.

\section{Reform of College Basketball Teaching Contents from the Perspective of Leisure Sports}

Reform of practice teaching. The reform of basketball teaching content should adapt to the development of physical education and meet the needs of students for leisure sports. Basketball teaching should change the traditional teaching concept, reduce the requirements of skills and action norms. Skills are important for basketball learning, but basketball teaching should meet the needs of students' physical and mental health and their personality development. In the process of daily basketball teaching, teachers should pay less attention to basketball skills and action standards. They need to combine basketball teaching with leisure sports, and introduce the concept of leisure sports into basketball teaching, in order to stimulate students' interests in basketball learning. This is helpful to improve students' enthusiasm to learn basketball, so as to achieve the purpose of physical and mental relax.

Teachers can introduce fancy basketball into college basketball teaching, and rich the forms of leisure sports. In order to improve students' interests in basketball learning, stimulate their potential, and make them more active in basketball class, teachers can introduce fancy basketball into their teaching process. Fancy basketball and ordinary basketball have great differences. Fancy basketball does not have uniform requirements, so every student can find the most suitable way to play. Fancy basketball is a new kind of sports which combines fitness and entertainment. There are a lot of activities in fancy basketball. Traditional Chinese basketball lays too much emphasis on rules and skills; fancy basketball breaks traditional norms. It combines techniques with tricks, and emphasizes the ornamental value of actions. It is a new kind of basketball, and can bring students with the joy of playing and watching basketball. Fancy basketball is in line with students' pursuit of personality, and offers them with unique experiences. Mastering the skills of fancy basketball is challenging to students, but it can also stimulate their fighting spirit to constantly challenge and break through themselves.

The meaning of leisure sports should be expanded, and the contents of this game should be increased. Competitive basketball produces a sense of tension for students. They always treat usual practice as match, and can not relax themselves. Basketball needs to relax students. Thus, the competitive consciousness of students should be weakened, in order to allow them to better enjoy the pleasure of basketball. When students participate in more basketball games, they will learn the right attitudes towards basketball game. Increasing game contents helps students to take an optimistic 
attitude towards the game. Students can find the balance between competition and cooperation, and further explore their potentials. They can also understand to stand aloof from fame and success, and better enjoy the fun of basketball, since the ultimate purpose of basketball is to relax themselves.

Reform of theory teaching. In the traditional theory teaching of basketball, teachers tend to ignore the cultivation of students' sports culture and spirit, especially the culture and spirit of leisure sports. Sports culture is a kind of knowledge which needs students to understand. In basketball teaching, instructors not only need to teach students about the actual technical skills and essentials of actions, but also need to enrich their knowledge on basketball culture, so as to improve their theoretical and practical abilities. Therefore, in the process of basketball teaching, teachers should pay attention to the teaching of physical culture and sports spirit.

Theory teaching is very important in basketball teaching, because it enables students to learn more about the essence of basketball, and cultivates their sports spirit. Only students with sports spirit can realize self-values in basketball game. Theory teaching can also help students to understand the value of sports, and enhance their awareness of participating in sports practice.

\section{Reform of College Basketball Teaching Methods from the Perspective of Leisure Sports}

To improve the teaching effect, teaching methods are crucial. The traditional way of basketball teaching has many drawbacks. It pays too much emphases on the training of students and the regulation of specific movements. The key of basketball teaching is skill training. Under such teaching mode, students are passive in learning process. They are lack of initiative, since they just need to follow the teacher and complete each movement. Their interests in basketball are losing, along with their learning initiative and creativity. Hence, basketball teaching loses its original meaning. Therefore, basketball teaching methods are very important. Appropriate teaching methods can help students to learn basketball skills and enjoy the game at the same time. This is the essence of basketball teaching.

Autonomous learning. Autonomous learning method means to stimulate students' autonomy. Teachers can allow students to set up their own goals, and then give them a certain amount of time to learn independently. Autonomous learning can effectively stimulate students' interests and give full play to their potentials. In order to achieve the goals, students need to pay continuous efforts. This learning method is different from the traditional one, since students are masters of learning, and they do not need to listen to teachers' instructions from A to Z. This increases the joy of learning, and improves the learning effect. [3] This learning method meets the basic requirements of leisure sports. When students complete their goals, they will have a sense of achievement, which enhances their confidences, further stimulates their interest in learning, and makes full play of their learning potentials and creativeness.

Cooperative learning. Cooperative learning is a teaching method based on group cooperation. Basketball game requires cooperation; team spirit is necessary in the process of basketball playing. Cooperative learning can cultivate students' team spirit, and unity members of the same group. Cooperative learning can also improve students' learning enthusiasm and enhance their learning motivations. Many students have pressures when learning basketball, since basketball is a kind of competitive sport, which can produce a sense of tension. Team spirit is a good solution to this problem.

Game learning. Game learning method means to integrate the elements of game into basketball teaching. It is a learning method suitable for students. Basketball teaching is relatively boring; repetitive actions and traditional techniques will reduce students' learning interests. Game learning method can significantly improve the situation. Teachers can set some small games in basketball teaching, and combines basketball skills and action into these games to create a relaxed atmosphere of learning, and enable students to learn skills when playing games. The game learning method changes students' views on basketball teaching, enhancing their enthusiasm for learning, and representing the essence of leisure sports.

Understanding learning. The method of understanding learning means to cultivate students' tactical consciousness and decision making abilities. In the traditional method of learning, students 
need to practice a movement repeatedly. They are easily to get bored. The understanding learning method requires teachers to cultivate students' tactical consciousness, as well as their reaction capabilities in matches through actual combat practices. In this way, students are able to choose the best approaches to deal with different situations in actual fighting based on tactics they have learnt. This teaching process can fully develop students' tactical awareness, which not only effectively improve their basketball skills, but also cultivate students' reaction capabilities.

Small group learning. Small group learning method means, teachers allow students to become masters in basketball classes. A class is a small group; the teacher can ask students to form teams according to their own wishes. Members of the same team ought to think, analyze and solve problems together. Every student can express their ideas and opinions in the classroom, and explore the knowledge of sports initiatively. Small group learning method can significantly improve the teaching effect.

\section{Conclusions}

In today's society, leisure sports have become the main way of sports and leisure. [4] Under the guidance of physical education curriculum reform, many colleges and universities integrate leisure sports into basketball teaching. Leisure sports meet students' needs on physical education courses, and embody the concept of healthy basketball. Therefore, the integration of leisure sports into basketball teaching is of great significance to further deepen the reform of physical education courses in colleges and universities.

\section{References}

[1] X.W. Zhou, On some important issues of basketball teaching in colleges and universities, J. Journal of Beijing Sport University, 2014

[2] L. Luo, Deepening understanding of leisure sport and its development in China, Soochow University, 2015:66.

[3] R.L. Zhang, L. Wen, X.M. Huang, Theory and Experimental Research on Physical Education Curriculum Construction in Colleges and Universities, Beijing Sport University Press, Beijing, 2015.

[4] Y.G. Wu, The present situation and problems of researches on leisure sports in China and abroad, J. Journal of Shanghai University of Sport. 27 (2003) 39-43. 